Original Research Article

\title{
Study to compare the blood sugar profile of the patients on risperidone and olanzapine with divalproex sodium as the common base
}

\author{
Manjuprasad M. S., Vijayalaxmi M. K.*, Shreya Hegde, Kamal Sundar T.
}

\begin{abstract}
Department of Pharmacology, Father Muller Medical College, Mangalore, Karnataka, India

Received: 29 March 2017

Revised: 11 April 2017

Accepted: 27 April 2017

*Correspondence to:

Dr. Vijayalaxmi M. K.,

Email: drvijayalaxmimk@ gmail.com
\end{abstract}

Copyright: (C) the author(s), publisher and licensee Medip Academy. This is an openaccess article distributed under the terms of the Creative Commons Attribution NonCommercial License, which permits unrestricted noncommercial use, distribution, and reproduction in any medium, provided the original work is properly cited.

\begin{abstract}
Background: Bipolar Affective Disorder which previously was called as manic depressive disorder represents the sixth leading cause of disability. Several preliminary studies suggest that antipsychotic monotherapy or in combination with mood stabiliser have a better prognosis. This study was conducted to compare the blood sugar profile of the patients who are on risperidone and olanzapine with divalproex sodium as the common base.

Methods: It was a prospective, comparative, observational, hospital-based clinical study conducted between November 2013 to March 2015. 41 BPAD patients on Risperidone and 38 BPAD patients on Olanzapine were included. A brief history and examination were carried out and the data was entered in a proforma sheet. The investigations carried out were noted. Patients were followed up for a period of 12 weeks i.e. $2,4,8$ and $12^{\text {th }}=$ week and the data analysed using SPSS software. Adverse drug events if any were recorded.

Results: Our study included 79 treatment-naive patients among whom 17 $(21.5 \%)$ were women and $62(78.5 \%)$ were men. The polarity of the disease of the majority of the patients was mania at the time of diagnosis. The mean blood sugar levels in risperidone and olanzapine group at the time of diagnosis were $137 \mathrm{mg} \%$ and $111 \mathrm{mg} \%$ respectively and weights $62 \mathrm{~kg}$ and $63.5 \mathrm{~kg}$ respectively. There was a gradual increase in blood sugar levels and weight from 4th week. At the end of the 12th week, the mean blood sugar levels were $152 \mathrm{mg} \%$ and $164 \mathrm{mg} \%$, weights $65.5 \mathrm{~kg}$ and $69.5 \mathrm{~kg}$ in risperidone and olanzapine group respectively.

Conclusions: Olanzapine was found to have higher incidence and rapid increase in blood sugar levels which can easily be treated by switching over to another drug. It has been suggested that at least a baseline survey should be undertaken on the prevalence of diabetes in Indian population among patients exposed to antipsychotic drugs.
\end{abstract}

Keywords: Bipolar affective disorder, Hyperglycaemia, Olanzapine, Risperidone

\section{INTRODUCTION}

Bipolar Affective Disorder which previously was called as manic depressive disorder represents the sixth leading cause of disability. ${ }^{1}$ It brings severe high and low moods and changes in sleep, energy, thinking and behaviour. People with Bipolar Affective Disorder can have periods in which they feel overly happy and energised and other periods of low mood, sluggish and hopeless. In between these periods patient usually feels normal. ${ }^{2}$
Several preliminary studies suggest that antipsychotic monotherapy or in combination with mood stabiliser have better prognosis. ${ }^{3}$ The most commonly prescribed among them are risperidone and olanzapine. But there are very few data regarding the profile of these drugs on blood components.

Although the exact mechanism involved in the development of hyperglycaemia is poorly understood some of the hypothesis are put forward. Impairment in the action of insulin i.e. decreased sensitivity and 
increased resistance was identified about 50 years ago and then later confirmed in Australia. Atypical antipsychotics are widely used compared to the classical ones as these drugs lack extrapyramidal side effects. while many of the drugs are better tolerated while some case increased the incidence of hyperglycaemia. One of the suggested mechanism of development of hyperglycaemia in patients who are on antipsychotics is weight gain with these drugs. weight gain is one of the precipitating factors for the development of diabetes. ${ }^{4}$ Another possible mechanism suggested was action of drugs on serotonin receptors which have indirect effect on hyperglycaemia. ${ }^{5}$

This study was conducted to compare the blood sugar profile of the patients who are on risperidone and olanzapine with divalproex sodium as the common base.

\section{METHODS}

It was a prospective, comparative, observational, hospital based clinical study conducted between November 2013 to March 2015 in the department of Psychiatry, Father Muller Medical College Mangalore.

Patients of age group between 18 to 65 of either sex receiving risperidone or olanzapine with divalproex sodium as the common base were included in the study. Patients with serious medical disorder endangering life, pregnant and lactating women, patients judged clinically to be at serious suicidal risk and the ones on mood stabiliser other than divalproex sodium were excluded from the study.

41 Bipolar Affective Disorder patients on Risperidone were included in one group and 38 Bipolar Affective Disorder patients on Olanzapine were included in another group. A brief history and examination were carried out in each patient. The data was entered in a proforma sheet. The investigations carried out were noted. Patients were followed up for a period of 12 weeks i.e. $2,4,8$ and 12 th week. Adverse drug events if any were recorded.

\section{Statistical analysis}

Statistical analysis was performed using Microsoft Excel and SPSS software version 23. Descriptive statistics was applied to obtain the mean and frequency of the demographic and clinical data. Student's t-test was used to compare the differences in demographic and baseline clinical characteristics. Chi-square test was applied to test the association of the categorical variables. A $p$ value of $<0.05$ was considered significant.

\section{RESULTS}

Our study included 79 treatment naive patients clinically diagnosed to have bipolar affective disorder among whom $17(21.5 \%)$ were women and $62(78.5 \%)$ were men. Among 17 women 7 of them were on olanzapine group and 10 were in the risperidone group. Among 62 men 31 were in olanzapine group and 31 were in risperidone group (Table 1 and Figure 1).

\section{Table 1: The distribution of study sample according} to gender.

\begin{tabular}{|llll|}
\hline \multirow{2}{*}{ Gender } & $\begin{array}{l}\text { Drugs } \\
\text { Olanzapine }\end{array}$ & Risperidone & Total \\
\hline \multirow{2}{*}{ Female } & 7 & 10 & 17 \\
& $18.4 \%$ & $24.4 \%$ & $21.5 \%$ \\
\hline \multirow{2}{*}{ Male } & 31 & 31 & 62 \\
& $81.6 \%$ & $75.6 \%$ & $78.5 \%$ \\
\multirow{2}{*}{ Total } & 38 & 41 & 79 \\
& $100 \%$ & $100 \%$ & $100 \%$ \\
\hline
\end{tabular}

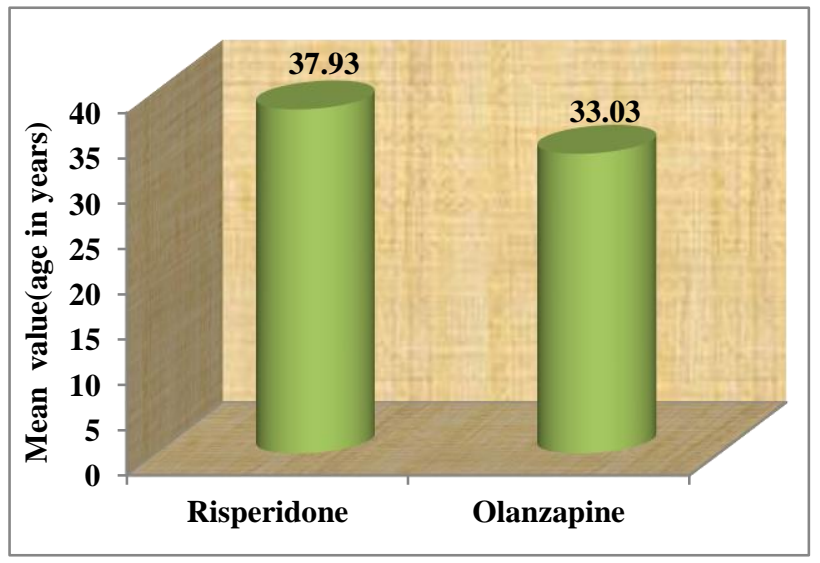

Figure 1: Distribution of the study sample according to the age.

The majority of the younger age group patients were in olanzapine group with the mean age at diagnosis was 22 years whereas the towards elderly age group patients were on risperidone with a mean age of diagnosis of 41 years (Figure 2).

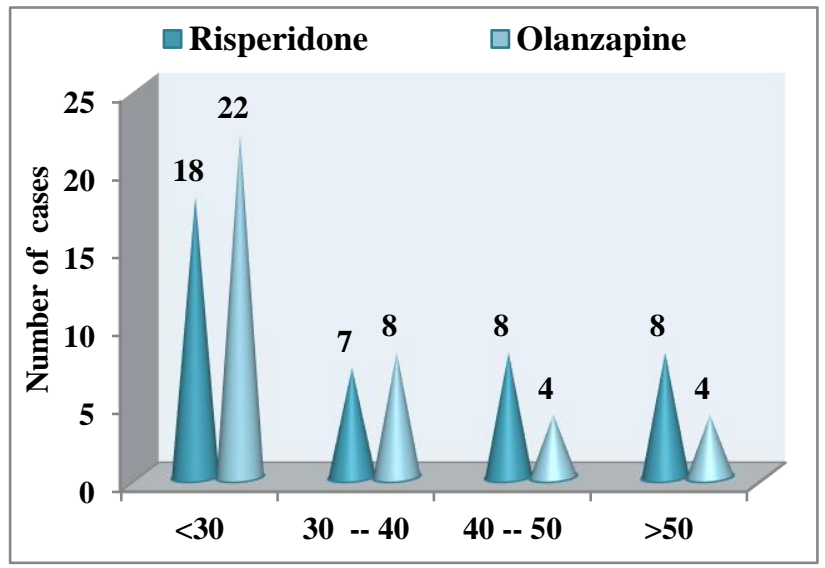

Figure 2: The age of diagnosis of Bipolar Affective Disorder.

The polarity of the majority of the patients was mania at the time of diagnosis. 
The mean blood sugar levels in risperidone and olanzapine group were at the time of diagnosis were $137 \mathrm{mg} \%$ and $111 \mathrm{mg} \%$ respectively and weights $62 \mathrm{~kg}$ and $63.5 \mathrm{~kg}$ respectively. There was a gradual increase in blood sugar levels and weight from 4th week. At the end of the $12^{\text {th }}$ week, the mean blood sugar levels were $152 \mathrm{mg} \%$ and $164 \mathrm{mg} \%$, weights $65.5 \mathrm{~kg}$ and $69.5 \mathrm{~kg}$ in risperidone and olanzapine group respectively (Figure 3 and Figure 4).

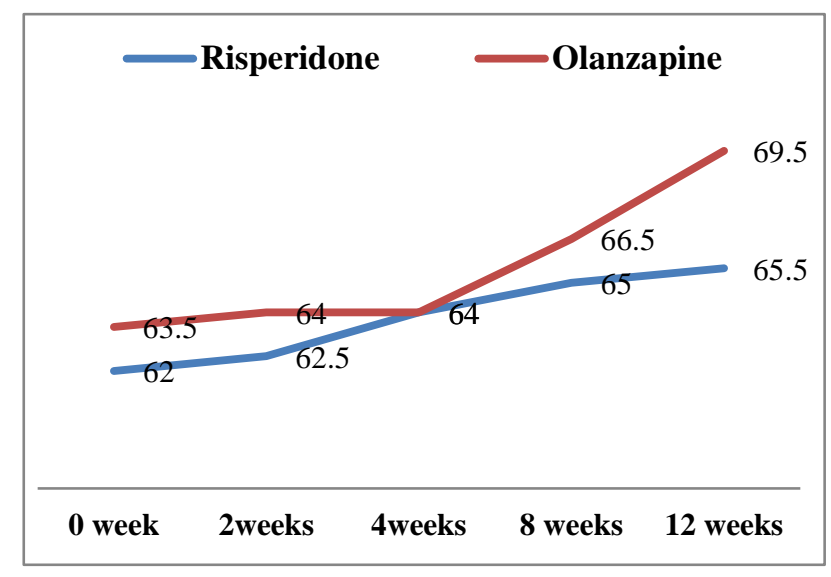

Figure 3: The mean weights of the patients on risperidone and olanzapine (over 12 weeks).

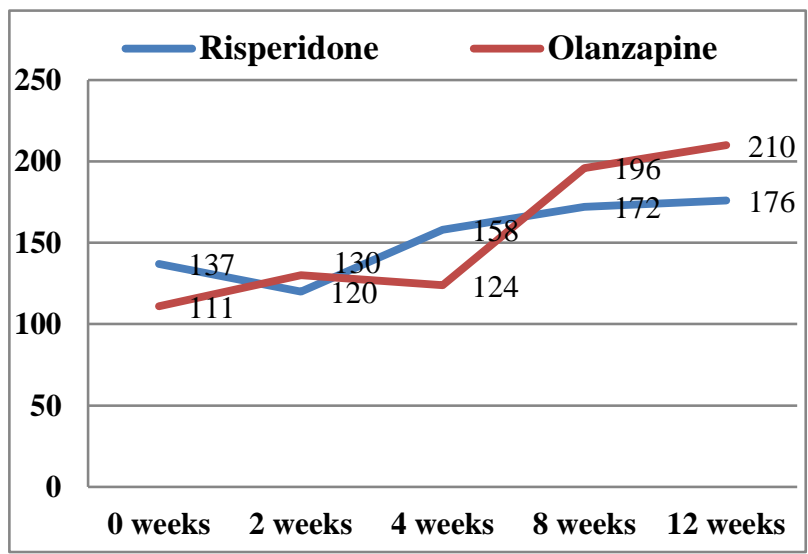

Figure 4: The mean blood sugar levels in risperidone and olanzapine group (over 12 weeks).

The adverse effects reported were minor which includes nausea, vomiting, headache, drowsiness, weight gain, raise in blood sugar levels.

\section{DISCUSSION}

Available literature on antipsychotic medication suggests that the patients taking these drugs are at a very high risk of developing diabetes. Of course, the drugs cannot be blamed alone for the development of hyperglycaemia as it has been proved that there are number of factors involved where the medication acts as one among them which includes, Overweight, ethnicity, family or personal history of diabetes mellitus or hypertension, and weight gain during the course of treatment. ${ }^{6}$

Even though the literature on bipolar affective disorder suggests there is no gender preponderance, in our study the majority of patients were men. ${ }^{7}$ This significant differences may be because men are likely to seek help and disclose their mental problems in a specialist health centre whereas women are more likely to seek help from a primary care physician. ${ }^{8}$

The advantage of using atypical antipsychotics is their lack of side effects, mainly the extrapyramidal side effects which are encountered with the use of older generation of antipsychotics. There are several suggested mechanisms on how antipsychotic drugs causes hyperglycaemia, but the exact mechanism is still unknown. However, there are differences among the individual drugs in the extent to which they can cause hyperglycaemia.

In our study, we found that both the drugs i.e. risperidone and olanzapine have equal tendency to cause hyperglycaemia. The patients were kept on a common mood stabiliser divalproex sodium. The rise in blood sugar levels started at the end of $4^{\text {th }}$ week and then increased gradually over a period of 12 weeks.

Which is accordance with the study done by Lindenmayer JP et al. ${ }^{9}$ Even though there was a rise in blood sugar levels none of the patient's values crossed normal limits. It was also seen that there was significant weight gain in olanzapine group compared to risperidone group similar to study done by Liberman et al. ${ }^{10}$ Blood sugar increase was also found to be more in olanzapine group compared to risperidone group over a period of 12 weeks and in one patient there was change in drug treatment from olanzapine to clozapine at $12^{\text {th }}$ week was done. which is in accordance with a study done by Smith $\mathrm{RC}$ et al. ${ }^{11}$

\section{CONCLUSION}

Since atypical antipsychotics are becoming more and more popular as a first line agent in the treatment of mood disorders, proper guidelines need to be established for monitoring blood glucose levels and determination of risk factors for diabetes mellitus. Olanzapine was found to have higher incidence and rapid increase in blood sugar levels which can easily be treated by switching over to another drug. It has been suggested that at least a baseline survey should be undertaken on the prevalence of diabetes in Indian population among patients exposed to antipsychotic drugs.

\section{Funding: No funding sources}

Conflict of interest: None declared

Ethical approval: The study was approved by the Institutional Ethics Committee 


\section{REFERENCES}

1. Barekatain M, Khodadadi R, Maracy MR. The outcome of the single manic episode in bipolar I disorder a six-month follow-up after hospitalisation. J Res Med Sci. 2011 Jan;16(1):56-62. PubMed: 21448384.

2. Swartz HA, Swanson J. Psychotherapy for Bipolar Disorder in Adults: A Review of the Evidence. Focus (Am Psychiatr Publ). 2014;12(3):251-66. PubMed: 2627964.1

3. Jeong JH, Lee JG, Kim MD, Sohn I, Shim SH, Wang $\mathrm{HR}$, et al. Korean Medication Algorithm for Bipolar Disorder 2014: comparisons with other treatment guidelines. Neuropsychiatr Dis Treat. 2015 Jun;11:1561-71.

4. Proietto J. Diabetes and Antipsychotic Drugs. Medsafe. 2004 [cited 2016 Dec 27]. Available from: http://www.medsafe.govt.nz/profs/PUarticles/antipsy chdiabetes.htm

5. Lindenmayer JP, Nathan AM, Smith RC. Hyperglycemia associated with the use of atypical antipsychotics. J Clin Psychiatry. 2001;62(23):30-8.

6. Benson V, Marano MA. Current estimates from the National Health Interview Survey [article online], 1995. Available from http://www.cdc.gov/nchs/data/series/sr_10/sr10_199a cc.pdf

7. Kawa I, Carter JD, Joyce PR, Doughty CJ, Frampton $\mathrm{CM}$, Wells JE, et al. Gender differences in bipolar disorder: age of onset, course, comorbidity, and symptom presentation. Bipolar Disord. 2005 May 7(2):119-25.

8. WHO | Gender and women's mental health. WHO. World Health Organization; 2013. Available from: http://www.who.int/mental_health/prevention/gender women/en/

9. Lindenmayer JP, Czobor P, Volavka J, Citrome L, Sheitman B, McEvoy JP, et al. Changes in glucose and cholesterol levels in patients with schizophrenia treated with typical or atypical antipsychotics. Am J Psychiatry. 2003 Feb;160(2):290-6.

10. Lieberman JA. Metabolic Changes Associated with Antipsychotic Use. Primary Care Companion to The Journal of Clinical Psychiatry. 2004;6(2):8-13.

11. Smith RC, Lindenmayer JP, Davis JM, Kelly E, Viviano TF, Cornwell J, et al. Effects of olanzapine and risperidone on glucose metabolism and insulin sensitivity in chronic schizophrenic patients with long-term antipsychotic treatment: a randomised 5month study. J Clin Psychiatry. 2009 Nov;70(11):1501-13.

Cite this article as: Manjuprasad MS, Vijayalaxmi MK, Hegde S, Sundar KT. Study to compare the blood sugar profile of the patients on risperidone and olanzapine with divalproex sodium as the common base. Int J Basic Clin Pharmacol 2017;6:1437-40. 